INDEPENDENT JOURNAL OF MANAGEMENT \& PRODUCTION (IJM\&P)

http://www.ijmp.jor.br

v. 11, n. 1, January-February 2020

ISSN: 2236-269X

DOI: 10.14807/ijmp.v11i1.993

\title{
NEUROMARKETING FOR A BETTER UNDERSTANDING OF CONSUMER NEEDS AND EMOTIONS
}

\author{
Elena Gurgu \\ Central Research Institute, Romania \\ E-mail: elenagurgu@yahoo.com \\ Ioana-Andreea Gurgu \\ University of Bucharest, Faculty of Psychology and Educational \\ Sciences, Romania \\ E-mail: gurguioana99@yahoo.com \\ Rocsana B. Manea Tonis \\ Central Research Institute, Romania \\ E-mail: rocsense39@yahoo.com
}

Submission: 1/25/2019

Accept: 5/2/2019

\section{ABSTRACT}

In this paper we are talking about the fact that marketing and publicity specialists have become aware of the limitations of traditional market research methods for decades, but only in recent years science has allowed the development of a more effective mechanism by which consumers' thoughts can be deciphered: neuromarketing. This term refers to the use of techniques developed by cognitive neuroscience and psychology specialists to analyze and understand people's reactions to products and promotions, which allows refining marketing efforts to make them more effective. In the article we are talking about the tools used for this purpose, which include magnetic resonance imaging (MRI), brain scanners that identify brain parts that react to different stimuli, and electroencephalography (EEG), devices that measure electrical activity in the brain. By tracking brain reactions to different stimuli, researchers can discover the marketing mechanisms that are most likely to lead to the desired outcome: selling the product. For this, in parallel with the EEG measurements, an eyetracking device is used, which allows the exact identification of the stimulus that produces the reaction from that moment. Also, some neuromarketing companies also use GSR (galvanic skin response) sensors to measure the electrical conductivity of the skin, which is another element that provides information about the consumer's response to various commercial messages. 
DOI: 10.14807/ijmp.v11i1.993

The purpose of our article is to show the role played by neuromarketing in the correct understanding of consumer needs, words and emotions.

Keywords: neuromarketing, neuroscience, product sale, advertising

\section{INTRODUCTION}

In the last decade neurosciences have seen tremendous development that has allowed a much better understanding of how different brain mechanisms work.

Neuromarketing is one of the newest branches of the advertising industry, being an emerging interdisciplinary field linking knowledge from psychology and neuroscience to marketing. This practice is not entirely new, because since the 1980s various experiments have been carried out to demonstrate the activation of certain areas of the brain when the consumer responds to certain products (KHUSHABA, 2013). Neuromarketing Technology Market Size was constantly increasing, as international statistics shows (Figure1). It is spread especially in North America and Europe.

The term was first used in the United States in the 1990s (Figure 2), and the first studies in the field were conducted by Gerald Zaltman, a professor from Harvard University. Several experts in this field have founded neuroscience companies, wishing to use new scientific tools outside of the academic world. (ZALTMAN, 2003). An example is offered by Gemma Calvert, who founded Neurosense in 1999, after a series of academic achievements such as obtaining a $\mathrm{PhD}$ in cerebral imaging at Oxford University and publishing papers in the prestigious Science and Nature journals. Neuroscience revolutionizes the medical world, the pharmaceutical industry, and even the economic sciences, their influence being much greater than world awareness (GEMMA, 2004).

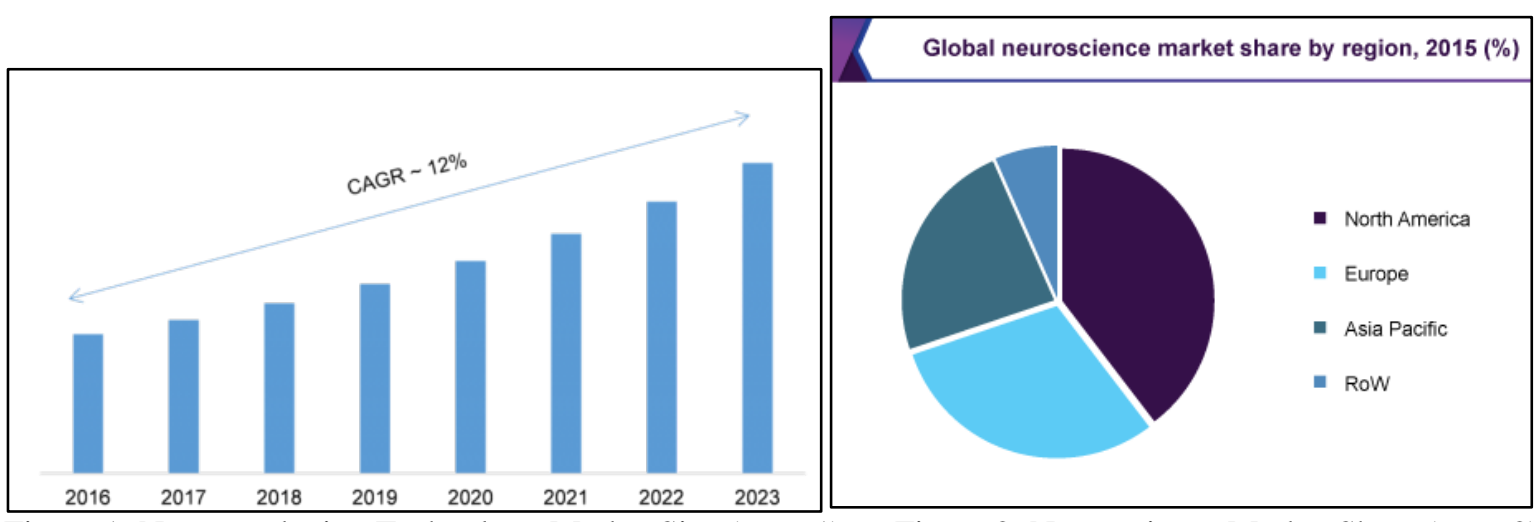

Figure 1: Neuromarketing Technology Market Size (www1)

Figure 2: Neuroscience Market Share (www2) 
INDEPENDENT JOURNAL OF MANAGEMENT \& PRODUCTION (IJM\&P)

http://www.ijmp.jor.br

v. 11, n. 1, January-February 2020

ISSN: $2236-269 X$

DOI: 10.14807/ijmp.v11i1.993

Professor Smidts used the term "Neuromarketing" for the second time in 2002. The term itself is based on the "neuron doctrine," a 19th century theory that says these specialized cells form the primary mechanisms of thought, despite the fact that neurons account for only $10 \%$ of the brain (SMIDTS, 2012).

The importance of this niche in the field of promotion is also demonstrated by the existence of a dedicated global association. In early 2012, the World Neuromarketing Association was launched, an institution that organizes the World Neuromarketing Forum each year.

The Neuromarketing Science \& Business Association (NMSBA, 2019), the world's first neuromarketing association, has as its mission and objectives the following: promotes the collective interests of neuromarketing professionals; contributes to the development and implementation of international standardization guidelines and to neuromarketing discipline; undertakes to deal with the recognition of discipline, professional ethics and professional codes to be respected; promotes the value of discipline in neuromarketing; encourages members to deepen their specialist knowledge; communicates recent results and knowledge about research among its members; communicates news about neuromarketing; brings together professionals and scientists at international level; protects general social interests related to neuromarketing; communicates information in national and international debates in the field.

Starting in 2012, the Neuromarketing World Forum (NMWF, 2019) is the annual event organized by NMSBA that focuses entirely on this emerging field, neuro-science research, consumer insights, and business outcomes. The purpose of the conference is to bring together both top-notch neuroscientific research and business professionals to discuss the main challenges and opportunities in using neuromarketing tools to enhance and add value to marketing research.

Organizers invite marketing directors, neuromarketing researchers, neurologists, media directors and, of course, people with a professional interest in neuromarketing. Only in the first year the event brought together not less than 100 researchers specializing in neuromarketing, who extensively discussed topics to help them in the further development of their projects.

Neuromarketing radically changed the way we understand the human brain. At this point, it is so advanced that it can predict how customers behave. Correct understanding of consumers' needs, desires and emotions is a huge challenge for any company that seeks to grow loyal customer base and create an effective CX (customer experience) strategy. 
DOI: 10.14807/ijmp.v11i1.993

This new science, neuromarketing, uses investigation of brain imaging and clinical psychology to discover what people think and feel when they look at prints, are exposed to messages from different brands, watch TV, shop, and browse internet, play video games or are trained in various activities.

Also, often called consumer neuroscience, neuromarketing is a sub-area of neuroscience that addresses relevant marketing issues with methods and perspectives from brain research. The essence of this science is to explore the human brain with images that bring positive emotional responses and which at the same time activate the stimuli on which a subsequent acquisition is based. So, the goal of neuromarketing is to discover exactly what people want, studying how the brain is physiologically affected by advertising and marketing strategies.

Theoretical neuromarketing gives us a new theoretical framework to understand consumer behavior and decision-making processes, especially the procurement process. Thanks to the theoretical neuromarketing, the simplified Homos Economicus model is left behind, and we can focus on how unconscious reactions influence people behavior and purchasing decisions.

The new patterns of human action explain the phases encountered by people before acting, comprising two unconscious and conscious phases:

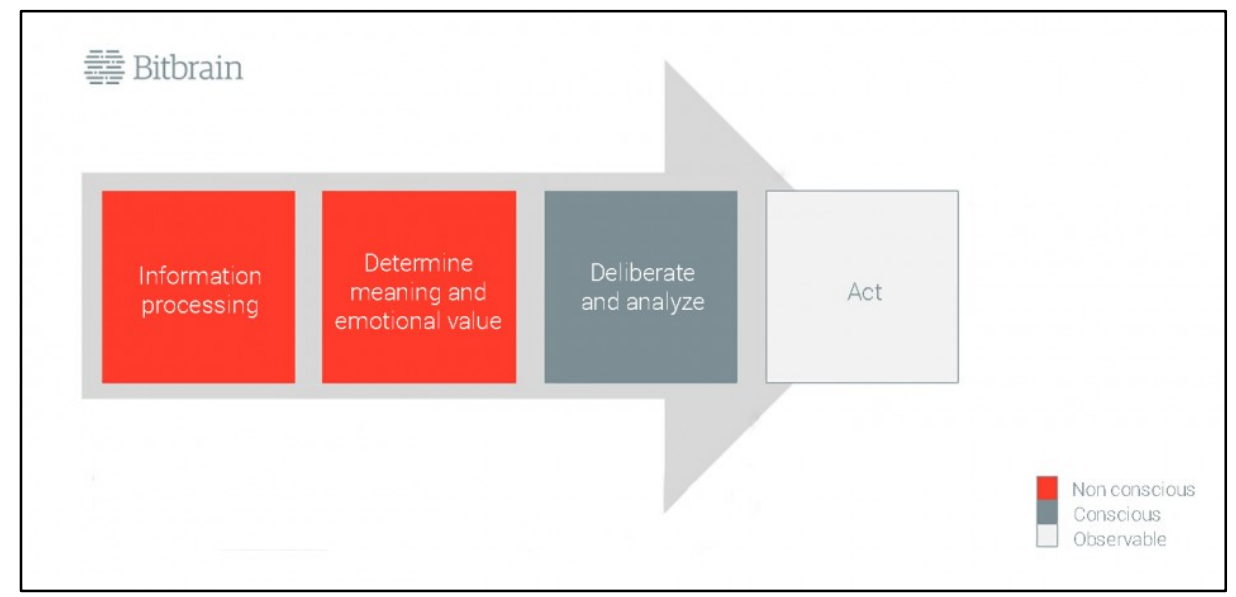

Figure 3: Bitbrain, 09.01.2019, All you need to know about neuromarketing, Source: https://www.bitbrain.com/blog/what-is-neuromarketing

1) Information processing: Attentional and unconscious processes are responsible for choosing what kind of stimuli attract our focus or not. This depends mainly on: i) whether these stimuli are different (attention from bottom to top); or (ii) if our brain 
DOI: 10.14807/ijmp.v11i1.993

thinks these stimuli are important (top-down attention). In the decision-making process, attention processes will be responsible for taking an option into consideration.

2) Determining the sense and the emotional value: our brain recognizes the information received by our senses non-consciously, and provides it with meaning and emotional value. That's why, when we make an unconscious decision, we already have a preferred option.

3) Deliberation and analysis: includes conscious cognitive tasks, such as recovering memories, interpreting the past, anticipating the future, planning, intentions generation, evaluation and judgment, simulation, problem solving, calculation and reasoning. This phase can make us choose an option, which is not necessarily the most attractive one from an unconscious point of view.

Neuromarketing studies consumer responses to marketing stimuli using neuroimaging techniques such as nuclear magnetic resonance, magnetic resonance imaging (MRNf), electroencephalography, encephalography (EEG), magneto-encephalography or brain topography (SST) (Figure 4). The process involves wiring subjects to various neuroimaging devices, requiring them to carry out experiential tasks and control tasks. These devices (e.g. MRI) generate instant, colorful images of the brain at work, and the researcher is able to compare the differences in the images produced during those tasks.

Then it becomes obvious which parts of the brain have responded to the used stimuli. This identifies certain parts of the brain that react differently to certain stimuli, and the specialists notice exactly which are the reactions that can lead to the desire to buy. Research has come to a level where a device is used that analyzes exactly where the viewer's eye is located, so no detail is accidental. Moreover, major research also uses GSR (galvanic skin response) sensors, which indicate exactly what the electrical conductivity of the skin is. So, brain activity is measured in certain areas of the brain to investigate how consumers make decisions and the link between decision making and human brain areas (SHARMA, 2016).

Neurostimulation Devices Market is in continuous increase, being dominated by North. 

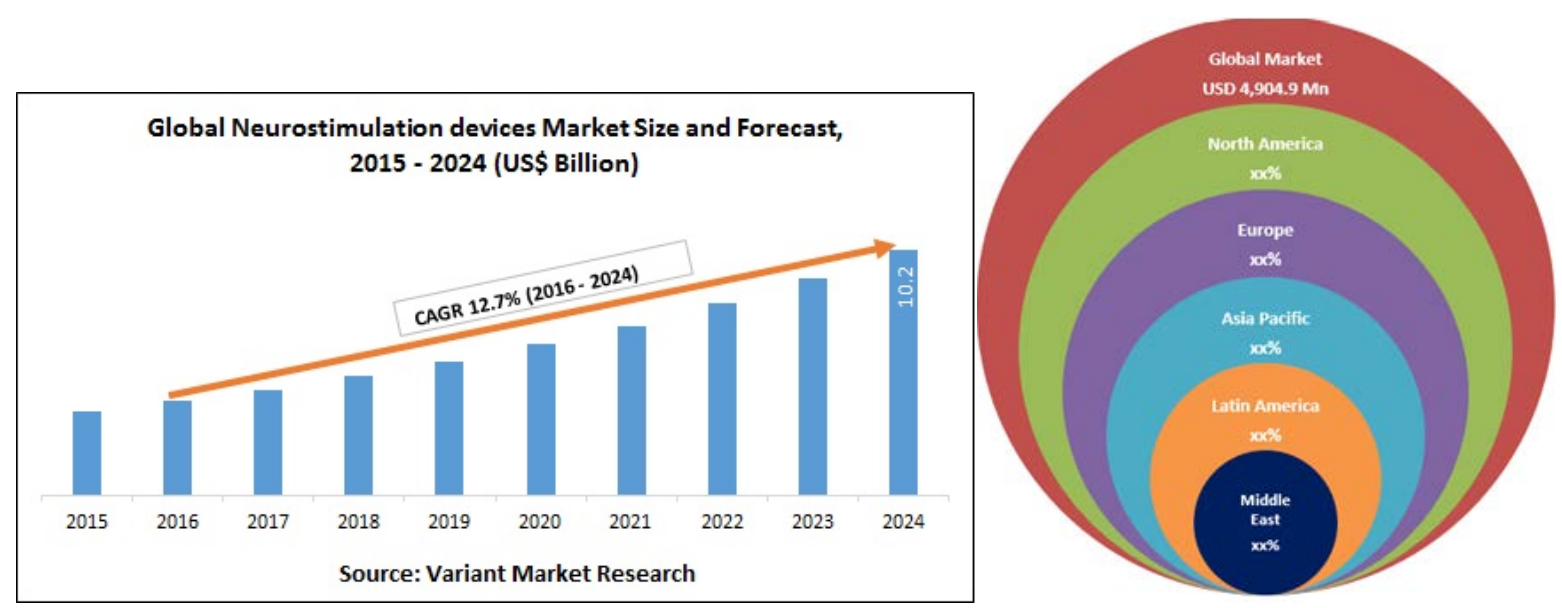

Figure 4: Neurostimulation Devices Market (www3)

So, neuromarketing fills this informational goal by surfacing with tools such as EEG, Eye-tracking or IAT - true "gold mines" untapped and extremely valuable to any company, regardless of industry. This is how the first graphic collages to stimulate different emotions have been made, and renowned companies such as Coca Cola, Nestle, Procter \& Gamble or General Motors have quickly embraced new techniques. Campbell, Frito-Lay, PayPal, Walmart, Home Depot, IKEA are not just the brands we've heard of, but are brands that understand that without neuromarketing they cannot keep up with consumers (NOTCH, 2015).

Given the new decision-making models, if we want to understand human behavior, especially consumer behavior, it's interesting to get information in each of the phases of this model:

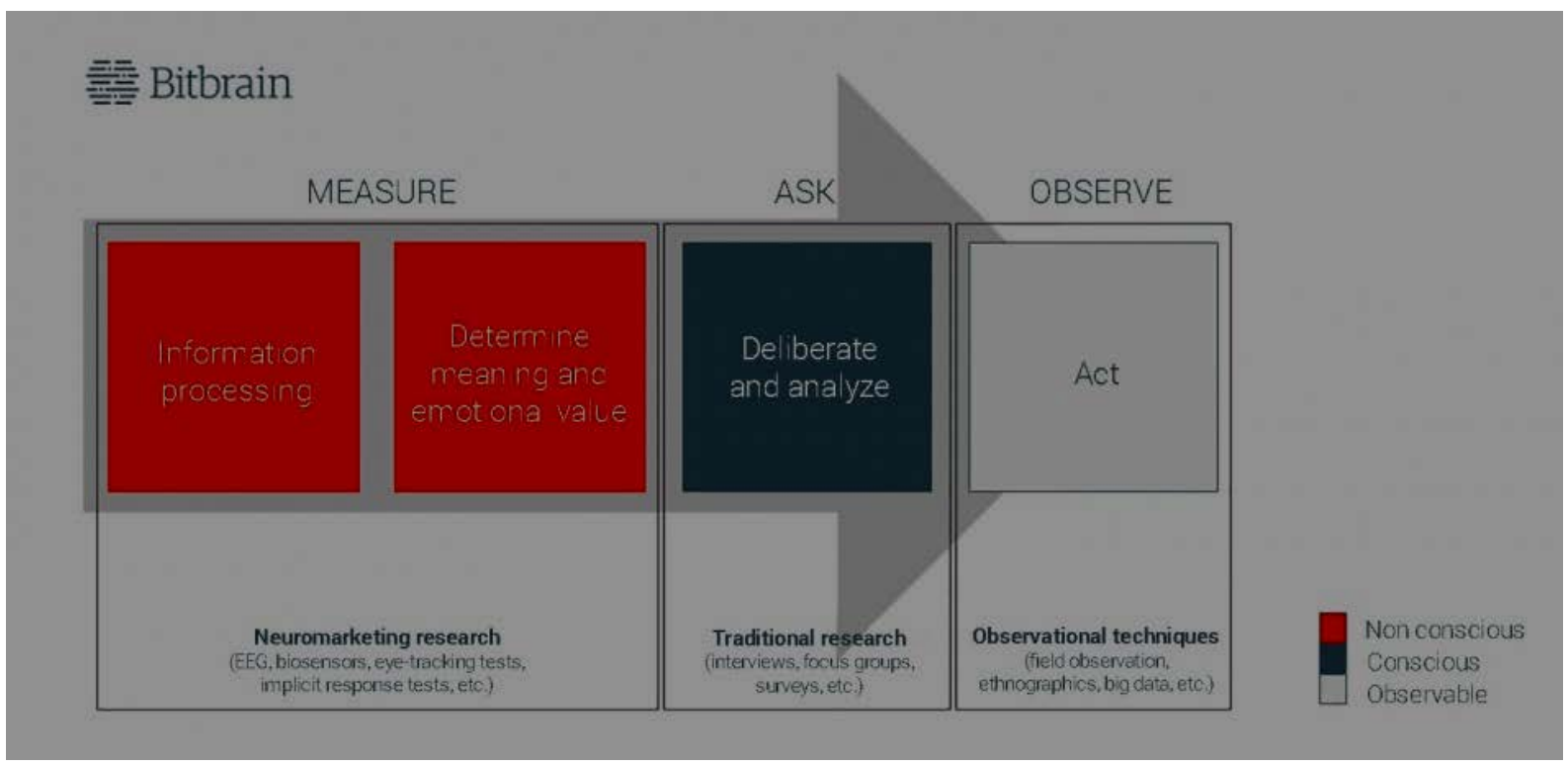

Figure 5: Bitbrain, 09.01.2019, All you need to know about neuromarketing

Source: https://www.bitbrain.com/blog/what-is-neuromarketing 
DOI: 10.14807/ijmp.v11i1.993

1) Observing the way the consumers act: there are several techniques in market research, like field observation, ethnography, big data for digital behavior, and even big data from the Internet of things (IoT).

2) Understanding the consumer's way of deliberate and analyze: as the deliberation and analysis phase is conscious, the companies can ask the consumer directly. The most traditional techniques to understand the consumer's decision from a conscious point of view are surveys, interviews and focus groups.

3) Analysing the consumers' unconscious reactions: These reactions are unconscious and are not observable and therefore can not be analyzed by the above mentioned techniques (traditional or observation). However, these unconscious reactions are generated in the brain and, in many cases, reflect on other areas of the body (e.g. sweaty hands when people are nervous). Due to the applied neuromarketing, it is possible to measure these physiological changes (with neurological instruments such as EEG or biosensors) and obtain the emotional or cognitive response that caused these changes through complex decoding algorithms. In this way, if a company wants to know the unconscious reaction of a consumer to an advertising campaign, for example, it can monitor the physiological changes produced while watching the spot and deduce the emotions that caused these changes.

The field evolves precisely from the need to better understand the consumer's decisions (identifying the cause and effect), measuring the moment-by-moment interaction for any type of stimulus, and reaching where traditional marketing has no access: in the subconscious. The market, as well as the individual behavior of consumers, is being analyzed using technologies that measure brain activity and a close connection is established between the exact reactions and the stimuli to which consumers have been exposed.

Neuromarketing can confirm, reconfigure, or improve the conventional theories of marketing theory. The classical methodology of market research that we are already familiar with is incomplete because it can only probe the consumer's consciousness, but not his subconscious. Some might say that such studies are also made in the forms of classic marketing, but the tools used in neuromarketing are brain scanners that use magnetic resonance imaging. All this is done in order to determine the exact reactions of the potential consumers.

\section{NEUROMARKETING - THE WAY NEUROSCIENCE CAN CONVINCE SOMEONE TO BUY}


DOI: 10.14807/ijmp.v11i1.993

The human brain uses only $2 \%$ of energy for conscious activity, most of its resources being dedicated to the subconscious. For this reason, most market researches cannot tell the true preferences of people, they find that reactions to a product are often impossible to explain in words. The majority of human thoughts and emotions are the result of this activity of the human subconscious, so that the actions triggered by them cannot be explained in a conscious approach (PEPPERELL, 2018).

Traditional research is based on getting a post-rational response, although about 98\% of our thoughts and actions come from the subconscious. Obviously, these answers are filtered and distorted by the very act of thinking the answer. Therefore, it is absolutely necessary to have means by which to measure people's reaction before their mind begins to rationalize the decision (JACKSON, 2019).

\section{THE APPLICABILITY OF NEUROMARKETING}

Beyond the innovative side of this concept, it has a very high applicability. The first goal is to elucidate the mystery of consumer purchasing decisions. This is expected to reduce the risk of leaving new advertisements, launching promotional campaigns and even placing products, as it provides clear evidence of consumer preferences, and even a new segmentation of buyers is expected.

Moreover, it would allow the identification of new techniques for influencing purchasing decisions and consumer loyalty. The benefits listed by neurologists go to reducing marketing costs by eliminating the possibility of waste money on certain products or techniques that would not work. However, given the novelty of this area, it is obvious that it would increase the cost of research due to the equipment used. However, if we talk about established brands or fierce competition from top brands, the benefits would overcome this obstacle. Neuromarketing can be implemented through virtual reality and have positive influence in the e-learning, too (BUCEA-MANEA-ȚONIȘ, 2018).

\section{HOW NEUROMARKETING WORKS}

How is an applied neuromarketing study performed? Performing an applied neuromarketing study is not just about putting the technology on the participant and demonstrating the stimulus we want to evaluate. The steps required for the correct study are:

1) Client Briefing: Fundamental to understand the client's real goals and needs in order to design a value-giving study. 
2) Definition of the sample to be included: The type of sample depends on customer information, no further considerations (if decoding computing models) other than those included in the traditional market study are required. As far as sample size is concerned, ideally at least 40 people should be included.

3) Technologies to include: Again, this depends on customer information and objectives, it is interesting to obtain specific values and therefore certain techniques are preferred. It is also very important to use high quality technologies to avoid a low reliability of results.

4) Designing the Experimental Protocol: A neuromarketing study is a neuroscience study, and therefore the design protocol must control many aspects and take many design decisions: what stimuli should be shown? For how long? In what order? Should be included rest periods? Is the study developed in a controlled context or in a real context? What kinds of tasks should the participants fulfill? How can the researcher control learning or order bias, etc? This is one of the most complex steps to become familiar with neuroscience.

5) Organize and execute field work: Depends on the objectives of the study, but a researcher can usually perform all field work related to a sample of 40 people within a week. Not to forget to prepare the informed consent form and dedicate an additional week to recruitment, implementation of the study (it is very important to have a good laboratory) and to carry out a small pilot study with 2-3 people to validate the procedure and train the staff.

6) Get Values: In the context of neuromarketing, it's convenient to rely on technology that delivers the desired values. It is important to know how to select a lab with good decoding algorithms.

7) Interpret the results: This is a key and difficult step because it means you can extract valuable information from your values and answer customer questions during the briefing. If more information is available (and from other sources), more value can be obtained from the study. The information should be synthesized to provide a positive outcomes report. 
DOI: 10.14807/ijmp.v11i1.993

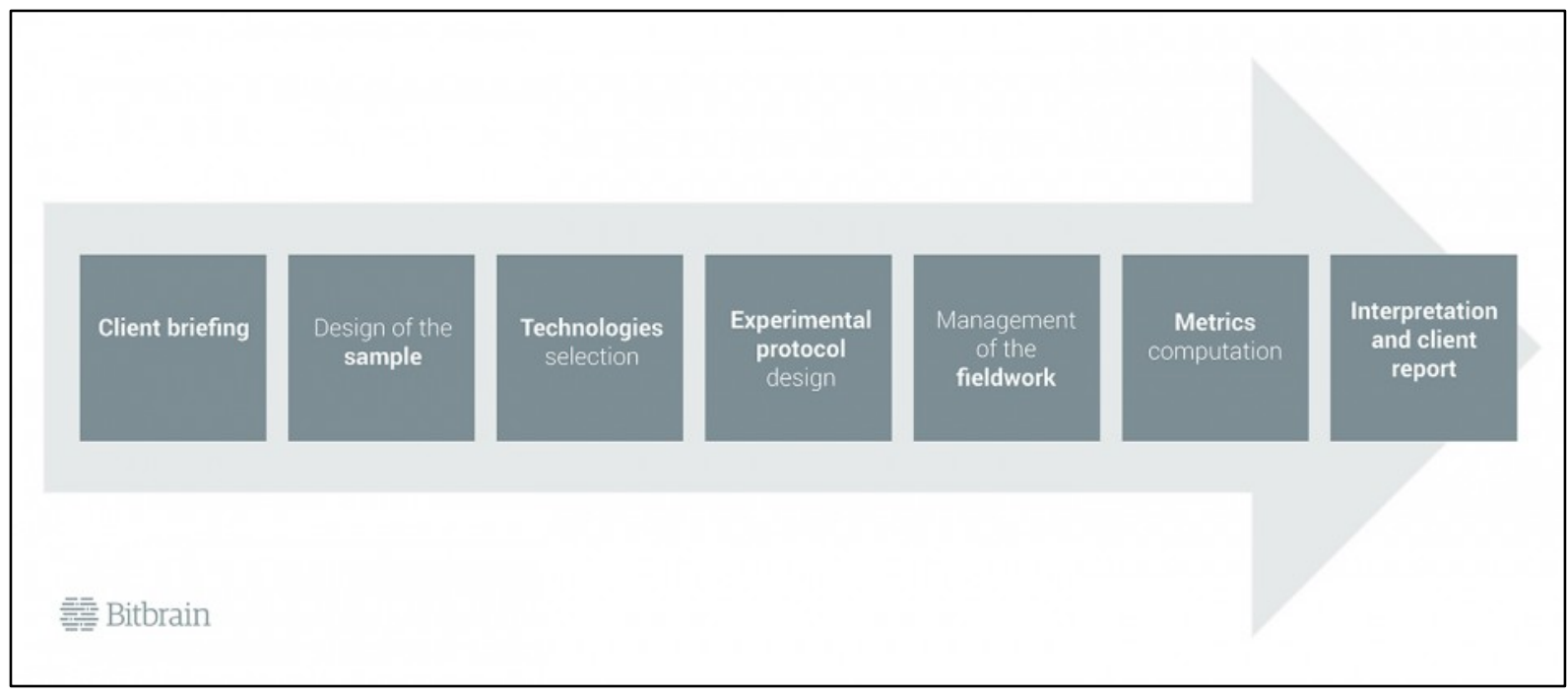

Figure 6: Bitbrain, 09.01.2019, All you need to know about neuromarketing Source: https://www.bitbrain.com/blog/what-is-neuromarketing

The New Scientist scientific journal has provided a case study that clarifies the functioning of neuromarketing. In August 2010, British magazine representatives made a fresh experiment: they chose the cover of the latest issue of the publication following tests by neuromarketers. The experiment was unexpectedly successful: sales recorded in August 2010 were $12 \%$ higher than those obtained in the same month of the previous year. Sales were certainly much higher than the magazine editors could expect for a cover with that subject at that time of the year, so they thought the experiment was a great success.

The cover had been chosen following tests by Californian Company, named NeuroFocus. The company's specialists tested three covers previously prepared by the editors of the magazine. Study participants were connected to EEG devices that measured their brain waves when they looked at the three variants. NeuroFocus representatives then recorded the three covers according to the data given by the electroencephalograph, analyzed using algorithms that measured factors such as "memory activation" and "emotional involvement." The cover of a magazine does not differ greatly from the packaging of a consumer product, and the Californian neuromarketing company has tested such objects many times.

Following the research, the specialists recommended the cover in which the name of the magazine was written in red letters (which stimulated emotional involvement of the reader) and the clearest picture of cosmic space (to reduce distraction factors). (MEDIndia, 2010).

Another company that has used neuromarketing-specific techniques to improve sales is Campbell, the most famous US brand of soups, made famous worldwide by Andy Warhol's works. The American company has collaborated with Innerscope Research, a Boston neuromarketing company, to collect biometric data from consumers' right in the supermarket 
DOI: 10.14807/ijmp.v11i1.993

to identify the elements underlying the purchasing decision. Following an ample effort to analyze how customers react in the supermarket, Campbell decided to modify the design of the famous soup boxes, eliminating images that did not produce an emotional reaction (spoons) and accentuating those who had emotional reactions from the customers - the steam rising from the plate (ILAN BRAT, 2010).

Another beneficiary of neuromarketing studies is Frito-Lay, a PEPSICO company from USA, who has called on NeuroFocus to design the packaging and ads for low-calorie chips to increase sales to women (PENENBERG, 2011). ESPN, the worldwide American TV channel who is a leader in sports, also turned to NeuroFocus to display sponsors' logos more effectively during sports broadcasts (NOAH FRANK, 2017).

\section{NEUROMARKETING TECHNIQUES TO IMPROVE ENTREPRENEURSHIP}

Neuromarketing is a discipline that studies the various reactions and actions that consumers have in the market. Its origins are found in advertising marketing but are more distinguished in brain responses that generate consumer impulses. One of the points that neuromarketing has studied is how it can connect with consumer sentiment in order to transmit values or emotions in relation to a particular brand.

Neuromarketing focuses on three main aspects: emotion, attention and memory. Based on these three concepts, neuromarketing first seeks the attention of the person viewing the ad, and then sends some emotion to the product. Eventually, the product is displayed when the person is already careful about the product so that they can later remember the brand.

What is the cause of the final decision to buy a product? Neuromarketing works primarily on products that are not essential goods, but which through persuasion people come to believe they need them.

Neuromarketing strategies are divided into three groups (BITBRAIN, 2019):

1) Vizual: focuses on how the client perceives reality in front of the eyes, such as placing prices at 0.99 for the mind of the observer, which means that 7.99 is cheaper than 8 ;

2) Hearing: In this case, you can set as example music that is heard in a particular store. If the store is intended for young people, usually the music that is heard is modern. This generates, for example, the desire to party.

3) Kinetic: This group covers sensations that are perceived by touch, taste and smell. In supermarkets often smell of freshly cooked foods, for example. 
DOI: 10.14807/ijmp.v11i1.993

Other aspects studied in neuromarketing are product positions and illumination or, for example, only the presence of large cars exposed to be won in supermarkets. The main objectives of neuromarketing are: maximize customer experience during shopping; stimulate customers with product and brand through the 5 senses; enhance how customers perceive brand information, process and assimilate them using assimilation techniques in sensitive memory; creating an impact on memory and emotional experience (FORTUNATO, 2014).

To achieve all these goals, there are people who use different techniques to measure impulses and reactions to products. These are some of the techniques that are used to elucidate these issues: functional magnetic resonances, watching the view (study of tracking movements), electromyography (analysis of the electrical response of the muscles), electroencephalogram (brain response analysis), face analysis (to determine what happens in the mind through facial expressions).

Here are four simple neuromarketing strategies that any entrepreneur can apply to his business to make his brand known to as many people as possible so he can optimize his sales (HEITZMAN, 2018):

a) Generating a deficit effect: The human being from Ancestral times have the instinct to limit food when it feels that there may be a shortage. This mechanism can also be found in modern man and is used by advertisers to increase sales. Therefore, if a company wants to sell a particular product, it can launch a campaign with a limited number of products so that the potential customer can buy the product before the shortage occurs;

b) Outlining pain and not pleasure: Neuromarketing has shown that action to avoid pain or complication is much stronger (at least three times more) than the sense of satisfaction. This is why it is important for companies to highlight the problem that their product will solve and not so much the benefits customers can get;

c) Stimulation of all senses: A current and very useful resource for advertising products is through video stories. These stories make potential clients identify with protagonists;

d) Using color in images and texts: Although it is an old advertising technique, it is still very effective because the brain continues to react in the same way. Companies must work with the colors most associated with their product (for example: blue color is associated with cleanliness, sincerity and honesty, green color is associated with health and nature).

\section{6. "HOT SPOTS" IN THE BRAIN, PRECIOUS TO A MARKETING MAN}


DOI: 10.14807/ijmp.v11i1.993

At the base of the brain are the so-called ventral striped bodies, which are the centers of pleasure. Activity in these centers indicates that the person feels good at that moment: for example, he feels the good taste of a meal or drink (ZURAWICKI, 2010).

Then the somatosensory cortex is another area that activates if a person is "involved" in mentally experiencing an experience, imagining it. Somewhat related to this, the mirror neuron system activates when we put ourselves in the role of the character we see, empathize with its state (GALLACE, 2014).

Finally (although the list is much longer), the medial prefrontal cortex is the center associated with personal identity. If we think of a car and our prefrontal medial cortex is activated, it means that the car fits our way of being. We want it! It's a sales predictor, even investigated at instinct level (SHARMA, 2010).

Functional MRI can provide answers to three crucial questions in advertising (Ariely, 2010):

1) whether a particular advertisement triggers an emotional reaction to the viewer;

2) if there remain items in that advertisement stored in the viewer's memory;

3) to what extent the ad has captured the attention.

These three variables can be measured by observing activation in different brain areas. More specifically, the emotional processing of an event is identified by functional MRI by sensing activation in a brain formation called "tonsillitis" (unrelated to the one in the throat that becomes red if we eat a lot of ice cream). The process of initiating memory is identified by sensing the activation of another formation called the hippocampus; and the capture of attention is reflected by the activation of a frontal-parietal network, which is an extended network of the brain that unites the frontal and parietal.

Questions such as "which of these 2 TV ads captures more attention / triggers more emotion / is more memorable?" answers best the MRI functionality. Moreover, emotional, attentional commitment and memory has proven to be a very powerful predictor of the success of an ad Thus, a study evaluating 24 ads and then measuring the sales growth rate due to their viewing found a correlation of 0.93 between sales growth and activation of the tonsil, hippocampus and fronto-parietal network. This shows that activating in the centers of emotion, memorization and attention predicts the success of an ad with an accuracy of 93\% (SZCZEPANSKI, 2013). 
DOI: $10.14807 /$ ijmp.v11i1.993

\section{WHO USES NEUROMARKETING?}

As we said, the first companies to use neuromarketing were the top ones, including luxury car manufacturers such as Mercedes or BMW, high volume sales companies such as Nokia or Procter \& Gamble, and many perfume manufacturers. Beyond these brands, neuromarketing is used for research and studies. One of the most recent such studies in Romania was linked to the impact of messages with or without images on cigarette packs. The conclusion of the study was that the impact of messages without images is minimal and far less ineffective than messages with frightening images, as the latter are emotionally processed.

Studies and actual results made in the USA. The use of specific neuromarketing research is different and the results are always surprising, providing new information about consumers.

An example of this is a study that demonstrates that not the grape variety nor the producing company are the two major pillars that an unrelated consumer takes into account when purchasing a bottle of wine. The experiment was conducted by specialists from the California Tech Institute in the United States of America. Analysts chose three bottles of wine, priced from \$ 5 per bottle and up to \$ 90 per bottle. Two of these types were offered to consumers both in bottles that looked luxurious and in modest packaging. In total, study participants therefore had five bottles of wine in front to taste them.

All the participants to the experiment were connected to special devices that measured their brain reactions, and each time the participants tasted a wine they considered to be an expensive one, part of the brain had a more intense activity. Interestingly, it was not the quality of the wine itself that stimulated this part of the brain, but the packaging in which it was offered, so the participants who thought they tasted an expensive wine always had the same positive reactions (DOOLEY, 2019)

Neuromarketing studies conducted in Romania. Most neuromarketing studies have been conducted in the UK and the US, but in recent years this area has gained more and more followers everywhere. Romania has become a member of this select club, with the first commercial research of neuromarketing in our country.

Buyer Brain is a Romanian company specializing in neuromarketing, and the first local study was the one made for a honey brand, Apicola Costache. The Romanian honey brand wanted to find out more about consumer perception of honey and how this food is appreciated. All this could be done quickly through an analysis based on the principles of neuromarketing. 
DOI: 10.14807/ijmp.v11i1.993

For this research the neuromarketing company used: an EEG device (electroencephalography), eye-tracking glasses and sensors that measure the electrical conductivity of the skin. The tools were also used to test the perception of product packaging compared to competition, as well as the visibility of the product on the shelf (CÎRNECI, 2014).

As a result of product shelf-life testing, it emerged that young and old people behave totally differently: if the subjects over 50 years have a straight line of sight, from center to left and then to the right, looking from top to bottom, from left to right, as a newspaper reads, young people leap left on the right in a rather chaotic way. These differences are rather related to the learning habits that the elders are more prominent because they were used to taking the information from the books, their gaze flowing in a similar way to reading. Young people used to surf the Internet jump from one extreme to the other as they look at the computer when surfing the Internet, chaotic moving from one item to another as they are used to following different links on a computer screen (KUMAR, 2016).

It was also found that the two age groups look at honey differently: elderly people consider it primarily a palliative treatment and young people look more like a substitute for sugar. The second study for the honey producer has analyzed what impact the label has on consumers. It has been found that the reason young people do not eat honey is that they get sticky.

The contractor who commissioned the first commercial neuromarketing study in Romania believes that research has brought concrete benefits to his company. The information obtained through the neuromarketing technique never came to light by traditional methods of market research. In order to maximize the investment he was planning to make in the rebranding and communication campaign, the Romanian entrepreneur preferred to go for sure with a neuromarketing research (CÎRNECI, 2014).

The main impediment in the development of this field in Romania is the high cost of the necessary equipment. In developed countries, there are partnerships between universities holding an fMRI and private companies that have access to carry out commercial studies. However, this is not happening in Romania for the time being.

\section{HUMAN NATURE - TOO COMPLEX FOR QUESTIONNAIRES}

Marketing has a twofold purpose: to guide the design and presentation of products in order to be as compatible with consumer preferences as possible and to facilitate the decisionmaking process of the latter. Marketing people accomplish these goals by providing product 


\section{INDEPENDENT JOURNAL OF MANAGEMENT \& PRODUCTION (IJM\&P)}

http://www.ijmp.jor.br

v. 11, n. 1, January-February 2020

ISSN: 2236-269X

DOI: 10.14807/ijmp.v11i1.993

designers with information about consumer values and desires before the product is created. Then, once the product enters the market, they try to maximize sales by guiding how the offer, options, price, advertising, and promotions are built. In their efforts to provide these inputs, they are using a wide range of market research tools, from focus groups and questionnaires to market tests.

In general, the simplest techniques (focus groups and questionnaires) are easy and inexpensive to implement, and over the past decades, people's views captured by the above techniques have been the primary source of information through which products have been pretested and also advertising campaigns. However, it is anecdotal the study in which the participants in a focus group on product hierarchy, at the end of the activity, were awarded even with the respective products, being left to choose what product they want. Someone registered the choices made, and there was no correlation between what they chose as a prize at departure and which product they declared to be the focus group preferred (RABIEE, 2004, OCHIENG, 2018)

It is known from psychology that the accuracy of the assessment of emotional states and thoughts through questionnaires and focus groups is quite dubious, for at least four reasons. A first reason would be that questionnaires and focus groups are often contaminated by a number of error factors, such as negligent responses or the tendency to please the one who leads the session, or the majority of opinion. In addition, completing a questionnaire takes time and is boring, and for many respondents the accuracy of responses is not always a priority.

Secondly, people are often not aware of their real feelings and emotions, so somebody is wondering what happened to realize that we are actually upset. Thirdly, even when people are aware of what they feel or think, they are not always honest in what they say because what they feel or do is not socially desirable (an example would be: how many bottles of beer have been drinking in the last week?). Finally, people are not very good at predicting future actions. So, which girl did not go into a store with the thought of buying a shirt and walked away with a pair of shoes?

\section{NEUROMARKETING SHOWS US THE REACTIONS DIRECTLY}

But if we could replace what people are saying with what happens in their brains? Can we see the brain in action directly without resorting to "interfaces" like questions? Research in neuroscience over the last 20 years has revealed that specific brain areas are activated during 


\section{INDEPENDENT JOURNAL OF MANAGEMENT \& PRODUCTION (IJM\&P)}

http://www.ijmp.jor.br

v. 11, n. 1, January-February 2020

ISSN: 2236-269X

DOI: 10.14807/ijmp.v11i1.993

various mind activities. These activations are deducted following the oxygen consumption achieved by these areas.

Thus, the more oxygenated (and therefore more active) areas appear on the screen of the computer coupled to an MRI as warmer in warm colors, while less oxygenated areas appear in colder or completely uncolored colors. More simply, what appears to be eating oxygen on the MRI is responsible for the mental activity at that time. Thus, a map of brain activity appeared, each mental activity being sought in a particular area (GORMAN, 2018)

Invented in the late 1990s by Gerald Zaltman from Harvard University, the neuromarketing aimed to decipher the underlying purchasing decisions by putting volunteers into MRI tubes or covering their heads with electrodes (ZALTMAN, 2003). Researchers then show them products, advertisements, and other marketing materials, and study the lines on the EEG, or follow the sangving flow of their brains on the images of the functional MRI. Apart from MRI and EEG, neuromarketing also uses MEG, transcranial magnetic stimulation (TMS), eye-tracking, and other computerized tasks.

What is very important is that neuromarketing tools provide data not only about what a consummate think, but also about how they react to a particular product or advertisement, that is, unconsciously. Activation in the brain is not under voluntary control, so the risk of error associated with focus groups and questionnaires is not present in this type of methodology.

Neuromarketing caused a sensation in the United States in 2003 when Read Montague of Baylor College of Medicine in Houston, Texas used functional MRI to explain a famous dilemma about Coca Cola and Pepsi: the two beverages are similar in the chemical composition and have only small taste differences, but Coca Cola maintained its dominant position on the market (THE GUARDINA, 2004).

In the experiment, a group of people drank Coca Cola or Pepsi while their brains were scanned with a functional MRI. Thus, it is relevant that different areas of the brain activate if people know the brand or not. According to the study, when people knew they were consuming Coca Cola, they said they preferred Coca Cola to Pepsi's detriment and activated their frontal lobe, an area that co-ordinates attention, controls short-term memory and directs thinking especially planning.

However, when they did not know the brand consumed, they reported that they preferred Pepsi, activating a structure in the limbic system that is responsible for emotional and instinctual behavior. Hence, it is highlighted that brands of products used as emotional stimuli 
DOI: 10.14807/ijmp.v11i1.993

influence cortical activity in the prefrontal ventromedial cortex and thus can influence purchasing behavior.

In conclusion, Montague and colleagues found that both in blind tasting tests, as well as in MRI scanning of the region of the brain responsible for taste, the subjects of the experiment were divided into their preference for the two brands, but more preferred Pepsi. But when they found out that they were drinking Coca Cola, the emotional and personal identity centers were disproportionately strongly stimulated - suggesting that Coca-Cola's cultural, brand image could cover the processing of taste by giving people another "reality" taste ". And then they said the drink was better. The results revealed that Pepsi has a privileged place in consumers' subconscious preferences, choosing Coca Cola not for reasons of taste, but because of their experience with the Coca Cola brand.

\section{THE PLUS VALUE OF NEUROMARKETING}

Neuromarketing can enter in a product cycle in several places. First, it can be used as part of a product design process. In this step, the brain's response can be used to test and refine the product before it is launched. For example, this methodology is widely used in food testing (yogurt, chocolate) at the level of pleasure associated with taste, smell, texture, each aspect can be studied separately, seeing which ones trigger more pleasure in the brain (SOUSA, 2017).

Second, it can be used after the product is ready, the brain response being used to measure the effectiveness of the promotion campaign. For example, the entertainment industry has been used to evaluate the success of a sitcom pilot called Curb Your Enthusiasm. It was found that the successful remembrance of its content over a period of 3 weeks after viewing was correlated with the degree of activation of the hippocampus during the viewing.

So, the more areas in the brain are more active while watching the movie, it means it has a bigger impact. This technique is also used to test movie trailers. That's why the trailers have such a great impact on us, they are making us curios to see the movie, and it's often a big difference between the feeling left after seeing the trailer and the feeling the movie gives you (SOUTHERTON, 2011).

Finally, neuromarketing techniques can be used to market segmentation, grouping consumers on the basis of "similar purchasing drivers" or, more briefly, by their brain model, and not just by traditional socio-demographic factors (age, gender, income, education). Moreover, neuromarketing can be applied to the most important marketing campaign: the political campaign. Studies have shown that activation of the medial prefrontal cortex is 
DOI: 10.14807/ijmp.v11i1.993

associated with maintaining preference for a candidate in response to the advertising campaign, while activity in its lateral area of the prefrontal cortex is associated with changing the preferred candidate (KUMAR, 2016)

\section{CURIOSITIES DECIPHERED BY NEUROMARKETING:}

a) How men's do brains work when they see naked women in chocolate or car commercials? It has been said that sex is selling, but neuro-studies show that things are not so, because the central element of the spot becomes the woman, and the viewer's brain no longer allocates resources to decode the message of his brand or to keep the information about it. If the role that a woman plays is closely related to the story of the spot and the message transmitted, the impact may be positive because the brain records that information together (CHUNG, 2015).

b) Effects on the brain of images with people who smoke and drink alcohol. On those who are not smokers or alcohol consumers, the pictures have no effect. A study conducted by the GSR on two groups of participants - consumers of Coca Cola and non-users showed that the advertising spot on the drink had no effect on those who did not consume it. But the consumer group displayed a high level of activation throughout the spot. On smokers or those who drink alcohol, the effect is craving. The phenomenon occurs due to the mirror neurons, with the role of brain-mimicking the action the participants see on the screen. Cerebral response also occurs in the non-consuming population, but is not followed by that craving - for them the reaction does not evoke any experience (ROBBINS, 2003).

\section{BENEFITS OF NEUROMARKETING FOR BOTH SIDES}

Companies dealing with the promotion of different solutions see the future of sales in the neuromarketing, but there are consumers who are very skeptical about this sector, believing that final decisions do not belong to them altogether. The truth is that neuromarketing is only another method by which specialists can find out exactly what attracts attention and what we really want, and if this information needs to develop solutions that are more suitable for consumers then all parties have something to gain. The products and services of the future will be made according to all our expectations, and companies will invest in product research and development where there is certainty that the demand will be high (SINGER, 2010) 
DOI: 10.14807/ijmp.v11i1.993

Neuromarketing studies are also very effective for companies. They allow the message to be optimized, so that the impact is the expected one. For example, after studying a video, we figure out which are the sequences that stir up the interest and which, on the contrary, irritates people or frustrates them because they do not understand the message (MORIN, 2011).

The effectiveness of the neuromarketing study is also reflected in the sales figures of a brand. Thus, ROI (return of investment) on the media budget will be much higher. However, sales of a product are related to several factors, not just advertising: logistics, product availability, price, and so on (NIKOLOPOULOU, 2016). Through the neuro-studies only some of these variables can be tested. A study in Germany tested the impact of coffee prices on consumers subconsciously and concluded that Starbucks demanded little for their product (KOTLER, 2017).

\section{NEUROETICS OR ETHICS IN NEUROMARKETING}

Commercial Alert (2003), an organization that aims to reduce the negative impact of advertising on the consumer, believes that neuromarketing aims to find inside the skull a button that activates buying. In terms of ethics, studies in Neuromarketing will never allow individuals to manipulate the minds of consumers or to get them to buy products that they do not need or do not like. Realistically, what can be done is to improve the way companies create and analyze their advertising messages, so they become more interesting, appealing and valuable to the target audience. The goal is to make changes within companies and not among consumers or their behavior (MADAN, 2010).

"The future of neuroscience will see the fuelling of neuroscience with ICT and future technologies. The robotics platform is a part of this, where neuromorphic chips that function like the human brain or the mouse brain or like brain circuits. This can be used, in the first instance, for brain simulation, but also for all sorts of other application, such as like artificial intelligence (AI) and neural networks. (FAUTEUX, 2019)”.

Nikki Westoby (2019), Director of Neuroscience at Nielsen Consumer Neuroscience, the largest market research company in the world, said recently in an article called The Future of Neuromarketing that “Consumer neuroscience’s much-improved diagnostics capabilities are rapidly making it an essential part of the creative process. Does it mean that we have all the answers now? Of course is not true. Human beings are complex. No single technology has a monopoly on the truth.” 
ISSN: 2236-269X

DOI: 10.14807/ijmp.v11i1.993

In our study we decided to analyze a time series that represents estimated total global neurostimulation devices market from 2013 to 2024 (in billion U.S. dollars). It was analyzed with Augmented Dickey-Fuller Test that shows the data was correct estimated and this means that neuroscience will have a fabulous spread in the future.

We even can create a pretty representative regression model: R-squared takes the value 0.92, meaning that with a 92\% probability the model coefficients are well estimated. The conclusion is supported also by the value of $\mathrm{F}$ test that is lower than 0.05. Durbin-Watson shows that there is no autocorrelation between variables. The trend is very well estimated. The p value for @TREND is $0.02<0.05$.

The coefficients for intercept (C) and Share variable could be better estimated. Their values are higher than 0.05 . (Table1). In table 1 Share variable is estimated total global neurostimulation devices market from 2013 to 2024.

Table1: Estimated total global neurostimulation devices market regression model (Dickey-

Null Hypothesis: SHARE has a unit root

Exogenous: Constant, Linear Trend

Lag Length: 0 (Automatic - based on SIC, maxlag=2)

\begin{tabular}{lccc}
\hline \hline & & & \\
& & & \\
& & & \\
Augmentatistic & Prob.* $^{*}$ \\
\hline Test critical values: & 1\% level & -0.530134 & 0.9594 \\
& $5 \%$ level & -5.124875 & \\
& $10 \%$ level & -3.933364 & \\
\hline \hline
\end{tabular}

*MacKinnon (1996) one-sided p-values.

Warning: Probabilities and critical values calculated for 20 observations and may not be accurate for a sample size of 11

Augmented Dickey-Fuller Test Equation Dependent Variable: D(SHARE)

Method: Least Squares

Date: 04/10/19 Time: 15:45

Sample (adjusted): 20142024

Included observations: 11 after adjustments

\begin{tabular}{lrllr}
\hline \hline \multicolumn{1}{c}{ Variable } & Coefficient & Std. Error & t-Statistic & Prob. \\
\hline \hline \multicolumn{1}{c}{ SHARE(-1) } & -0.040329 & 0.076074 & -0.530134 & 0.6104 \\
C & 0.050787 & 0.110830 & 0.458242 & 0.6590 \\
@TREND("2013") & 0.056483 & 0.019665 & 2.872306 & 0.0208 \\
\hline \hline & & & \\
R-squared & 0.923399 & Mean dependent var & 0.272727 \\
Adjusted R-squared & 0.904249 & S.D. dependent var & 0.160255 \\
S.E. of regression & 0.049589 & Akaike info criterion & -2.943095 \\
Sum squared resid & 0.019673 & Schwarz criterion & -2.834579 \\
Log likelihood & 19.18702 & Hannan-Quinn criter. & -3.011500 \\
F-statistic & 48.21862 & Durbin-Watson stat & 2.327106 \\
Prob(F-statistic) & 0.000034 & & \\
\hline \hline
\end{tabular}


DOI: 10.14807/ijmp.v11i1.993

When we are talking about the future of neuromarketing and what are the challenges that people have to face, we may think about:

1) Transmit the value added of neuromarketing: The insights obtained with neuromarketing cannot be obtained otherwise. Also, the insights can be acted upon to improve the brand or product, communication, purchasing experience, etc. There is still unawareness on what neuromarketing can offer. Rigorous dissemination of neuromarketing contributions is required.

2) Accessible: New laboratories that include simple, easy-to-use technologies, predesigned studies and decoding algorithms can be used by any professional without a background in neuroscience. In terms of prices, high quality professional labs are available starting at $€ 8,000$.

3) There are no B2C or B2B companies; we are talking about $\mathrm{H} 2 \mathrm{H}$ companies: Marketing is becoming more and more human, not only focusing on the customer relationship, but on the person, with his emotions and values. Therefore, it is necessary for marketing professionals to have a holistic view of the human being. This is only achieved by integrating neuromarketing techniques with other complementary research techniques.

4) The technological revolution is here. To survive, we need to innovate: the customer wants innovation and wants to be surprised. Neuromarketing brings innovations to market research institutes and also to brands while accessing new consumer information.

5) Fight against the unethical attitudes that generate the "fear" of neuromarketing: Since this is a new field, there are false news about neuromarketing and not much information overall. For example, some specialists defend the existence of the purchase button in the brain, which could be a priori a good sales argument, but it is unethical, it is not true and generates rejection from the society.

6) Searching for standards: As a new domain, there are no standard values so that each neuromarketing company uses its own values. Thus it becomes complex to compare results if you switch among providers.

Technology analysts mention that wearable revolution is close - in other words, wearable technologies with biosensors. Nowadays, there are examples of such types of devices: Fitbit, Xiaomi Mi band and the Apple Watch, which are designed primarily to monitor physical status. However, although the quality of the physiological signals currently recorded is not 
DOI: 10.14807/ijmp.v11i1.993

accurate enough to be used in the neuromarketing environment, it is only a matter of time until the precision of the equipment improves. Eventually, neuromarketing will cease to be used in controlled contexts and will begin to be utilized massively, anywhere, by any person, thanks to these devices.

Eventually, technology analysts say the bearer's revolution is close - in other words, technologies that can be worn with biosensors. Nowadays there are examples of such types of devices: Fitbit, Xiaomi Mi and Apple Watch, which are mainly designed to monitor physical activity. However, although the quality of recorded physiological signals is currently not sufficiently precise to be used in the neuromarketing environment, it is only a matter of time to improve the precision of the equipment. Eventually, neuromarketing will cease to be used in controlled contexts and will be widely used, anywhere, by any person due to these devices.

\section{INSTEAD OF CONCLUSIONS: WHAT DOES THE FUTURE PREPARE US FOR?}

Neuromarketing is not the only innovation that allows a better understanding of the consumer. Thanks to technological advancement, marketers have access to a growing amount of customer data, and the growing computational capacity allows them to be analyzed to identify buying intentions. The American company Target has become the target of critics after the New York Times reported a case in which hypermarket statisticians identified the products that women buy in the first month of pregnancy.

Another technology, developed by Affectiva, allows computers to automatically evaluate people's facial reactions and instantly understand their reactions to commercials and other alike communications. Affectiva's representatives say that the growing number of camcorder devices, from mobile phones to laptops, will make the interpretation of a person's emotions easy to read in most moments.

In the future, smart phones could allow companies to drive ads much more efficiently than today. A patent demanded by Verizon's Mobile Phone Company shows how this system works: for example, a couple begins to quarrel at the TV in their own living room. An algorithm detects the domestic dispute, so the TV automatically selects an advert for a local therapist specializing in couple issues for the next advertising pause. As each of us produces more data, through search engines, social networks, smart phones or intelligent sensors installed in shopping centers, and computational capacity grows, companies will come to understand us much better. 
DOI: 10.14807/ijmp.v11i1.993

This progress is promising to deliver multiple benefits: on the one hand, the general public will have products carefully designed to meet its needs, and the natural and human resources that have been missed today by unsuccessful products will be used more efficiently. Today, statistics show that about $80 \%$ of new products are failing in the first year of launch. Therefore, a better understanding of consumers and the refinement of marketing techniques could lead to wiser, more efficient and more friendly nature.

The effects of neuromarketing have not yet been debated, so it is not clear whether it is ethical or not. Neuromarketing is like a Pandora's Box, but it's not necessarily bad. Neuromarketing should be treated with caution, because we do not know all the consequences it may involve, there are many confusions and misunderstandings, many expectations, many challenges, but also many boundaries related to the human brain.

Neuromarketing is mostly used in advertising. And in advertising you cannot respect the concept of privacy when you are in an agency of this type and you must use neuromarketing for a particular product. Communication is not a science, it is a dialogue. Brands should talk to consumers, and in branding people need to be involved. This communication must be seen in the behavior of the consumer, that he returns to the product, this being the essence and promise of advertising. If the company wants to communicate a message to the customer, then it has to let him know it.

\section{REFERENCES}

ARIELY, D.; BERNS, G. (2010) Neuromarketing: the hope and hype of neuroimaging in business. Nature Reviews Neuroscience, v. 11, n. 4, p. 284-292

BITBARIN (2019) All you need to know about neuromarketing, https://www.bitbrain.com/blog/what-is-neuromarketing

BUCEA-MANEA-ȚONIȘ, Ro.; ANDRONIE, M.; IATAGAN, M. (2018) E-LEARNING IN THE ERA OF VIRTUAL REALITY, The 14th International Scientific Conference eLearning and Software for education, Bucharest, April 19-20, v. 1, p. 363-369, DOI: 10.12753/2066-026X-18-050

CHUNG, E. (2015) Neuromarketing: Marketers Scan Consumers' Brains To Test Their Ads, CBC News.

CIRNECI, D.; ANGHELUTA, A. V.; GHEORGHE, D. (2014) The Use of Neuromarketing in the Study of Brand Related Mental Processes. Case Study - Romanian Food Brands, International Journal of Economic Practices and Theories, v. 4, n. 2

DOOLEY, R. (2019) College Branding: The Tipping Point

FAUTEUX, C. (2019) SCITECH EUROPA. The progress and future of the Human Brain Project. https://www.scitecheuropa.eu/human-brain-project/92951/, www.humanbrainproject.eu/en/ 
FORTUNATO, V. C. R.; GIRALDI, J. M. E.; OLIVIERA, J. H. C. (2014) A Review of Studies on Neuromarketing: Practical Results, Techniques, Contributions and Limitations, Journal of Management Research, v. 6, n. 2, p. 201-220 https://doi.org/10.5296/jmr.v6i2.5446

GALLACE, A.; SPENCE, C. (2014) In touch with the future: The sense of touch from cognitive neuroscience to virtual reality. Oxford University Press, DOI: 10.1093/acprof:oso/9780199644469.001.0001

GEMMA, C.; SPENCE, C.; STEIN, BARRY E. (2004) The Handbook Of Multisensory Processes. A Bradford Book, The MIT Press Cambridge, Massachusetts, London, England GEMMA, C.; BALANZÓ, C.; WATKINS, S. (2012) Opening The Black Box. An Academic Evaluation Of The Ability Of Electroencephalography (EEG) And Eye Tracking (ET) To Predict Advertising Effectivenes, Conference: Esomar Global Conference, Atlanta, USA, Https://www.Researchgate.Net/Publication/81147338_Esomar_2012_Opening_The_Black_B ox

GORMAN, J. M. (2018) Neuroscience at the Intersection of Mind and Brain, Oxford University Press

HEITZMAN, A. (2018) 4 Neuromarketing Strategies for Highest Content Impact 2018 https://www.inc.com/adam-heitzman/4-neuromarketing-strategies-for-highest-contentimpact.html

HILL, K. (2012) How Target Figured Out A Teen Girl Was Pregnant Before Her Father Did, Forbes, https://www.Forbes.Com/Sites/Kashmirhill/2012/02/16/How-Target-Figured-Out-ATeen-Girl-Was-Pregnant-Before-Her-Father-Did/\#3850b6f76668

HUBERT, M.; SOMMER, J.; KENNING, P. (2009) Consumer Neuroscience - the effect of retail brands on the perception of product packaging. Mark Rev St Gallen, v. 4, p. 28-33

ILAN, B. (2010) The Emotional Quotient of Soup Shopping, Campbell's Taps 'Neuromarketing' Techniques to Find Why Shelf Displays Left Some Customers Cold, The Wall Street Journal, https://www.wsj.com/articles/ SB10001424052748704804204575069562743700340

JACKSON, J. (2019) Being Stuck Isn’t Your Fate - 3 Ways To Overcoming It, Conscious Magazine, Https://Consciousmagazine.Co/Stuck-Isnt-Fate-3-Ways-Overcome/.

KENNING, P., LINZMAJER, M. (2011) Consumer neuroscience: an overview of an emerging discipline with implications for consumer policy. Journal of Consumer Protection and Food Safety, v. 6, p.111-125

KHUSHABA, R. N.; WISE, C.; KODAGODA, S.; LOUVIERE, J.; KAHN, B. E.; TOWNSEND, C. (2013) Consumer Neuroscience: Assessing The Brain Response To Marketing Stimuli Using Electroencephalogram (EEG) And Eye Tracking. Expert Systems With Applications v. 40, p. 3803-3812, Elsevier

KOCINA, L. (2017) What Percentage Of New Products Fail And Why?, Media Relations Agency, Marketsmart Newsletters, https://www.Publicity.Com/ MarketsmartNewsletters/Percentage-New-Products-Fail/

KOENIGS, M.; TRANEL, D. (2008) Prefrontal cortex damage abolishes brand-cued changes in cola preference. Social Cognitive and Affective Neuroscience, v. 3, p. 1-6 
DOI: 10.14807/ijmp.v11i1.993

KOTLER, P. (2017) Consumer Neuroscience. The MIT Press, Cambridge, Massachusetts Institute of Technology, London, England, p.15

KOTLER, P.; ARMSTRONG, G. (2018) Principles Of Marketing, Global Edition, Pearson Educational. Ltd, UK

KUMAR, H.; MATHUR, N.; JAUHARI, S. (2016) Neuromarketing: A New Agenda For Marketing Researches With Particular Reference To Eye Tracking, International Journal of Core Engineering \& Management (IJCEM), v. 3, n. 2, Http://Ijcem.In/WpContent/Uploads/2016/06/A-New-Agenda-For-Marketing-Researches-With-ParticularReference-To-Eye-Tracking-NEW.Pdf

MADAN, C. R. (2010) Neuromarketing: The Next Step In Market Research?, Eureka, v. 1, n. 1

MAHIMA, S.; SUDHANSHU, K.; MOHIT S. (2018) A Brief Introduction and Review On Galvanic Skin Response. International Journal Of Medical Research Professionals, PIssn: 2454-6356, E-Issn: 2454-6364, Doi:10.21276/Ijmrp

MCDUFF, D.; EL KALIOUBY, R.; KODRA, E.; LARGUINAT, L. (2013) Do Emotions In Advertising Drive Sales? Use of Facial Coding To Understand The Relationship Between Emotional Responses To Ads And Sales Effectiveness, Affectiva, Research Paper https://www.Affectiva.Com/Wp-Content/Uploads/

2017/03/Do_Emotions_InAdvertising_Drive_Sales_Use_Of_Facial_Coding_To_Understand _The_Relati.pdf

MEDINDIA (2010) Apply Neuromarketing To Select Cover Design. Neurofocus And New Scientist Magazine, https://Www.Medindia.Net/Health-Press-Release/Neurofocus-AndNew-Scientist-Magazine-Apply-Neuromarketing-To-Select-Cover-Design-77974-1.html

MORIN, C. (2011) Neuromarketing: The New Science of Consumer Behavior. Symposium: Consumer Culture in Global Perspective v. 48, p.131-135, DOI 10.1007/S12115-0109408-1

MURPHY, E. R.; ILLES, J.; REINER, P. B. (2008) Neuroethics of neuromarketing. Journal of Consumer Behaviour, v. 7, p. 293-302

NIKOLOPOULOU O. M, POLLALIS Y. A., SAMANTA I. (2016) Building a Successful Brand Using Information Design And Neuromarketing Principles, Syndicate, The Journal of Management, v. 16, ISSN 2278-8247

NMSBA (2019) Neuromarketing Science \& Business Association, https://www.nmsba.com/ NMWF (2019) Neuromarketing World Forum, http://neuromarketingworldforum.com/

NOTCH. (2015). Neuromarketing: Pseudoscience Or The Future Of Advertising?, https://www.Notchcommunications.Co.Uk/Neuromarketing-Pseudoscience-Or-The-FutureOf-Advertising/

OCHIENG, N. T.; WILSON, K.; DERRICK, C. J.; MUKHERJE, N. (2018) The use of focus group discussion methodology: Insights from two decades of application in conservation.

Methods Ecol Evol., n. 9, p. 20-32. https://doi.org/ 10.1111/2041-210X.12860, https://espace.library.uq.edu.au/view/UQ:717616

PEPPERELL, R. (2018) Consciousness As A Physical Process Caused By The Organization Of Energy In The Brain. Frontiers In Psychology, v. 9, p. 2091. Doi:10.3389/Fpsyg.2018.02091 
DOI: 10.14807/ijmp.v11i1.993

PENENBERG, A. (2011) NeuroFocus Uses Neuromarketing To Hack Your Brain, https://www.fastcompany.com/1769238/neurofocus-uses-neuromarketing-hack-your-brain

RABIEE, F. (2004) Focus-group interview and data analysis. Proceedings of the Nutrition Society, v. 63, n. 4, p. 655-660. doi: 10.1079/PNS2004399

REIMANN, M.; SCHILKE, O.; WEBER, B.; NEUHAUSM C.; ZAICHKOWSKY, J. (2011) Functional Magnetic Resonance Imaging in Consumer Research: A Review and Application. Psychology and Marketing, v. 28, n. 6, p. 608-637

ROBBINS, P. R. (2003) Understanding Psychology. 3rd Edition, J. Weston Walch Publisher, Portland, Maine, USA, p. 50

SOUSA, J.; COUTINHO. (2017) Neuromarketing And Big Data Analytics For Strategic Consumer Engagement: Emerging Research And Opportunities, IGI

Global, https://Books.Google.Ro/Books?Id=Ltdcdwaaqbaj\&Dq=Neuromarketing+As+Part+ Of + A+Product+Design+Process \&Hl=Ro\&Source=Gbs_Navlinks_S

SINGER, N. (2010) Making Ads That Whisper To The Brain, https://www.Nytimes.Com/2010/11/14/Business/14stream.Html

SOUTHERTON, D. (2011) Encyclopedia Of Consumer Culture. Volum 1, SAGE Publisher, University Of Menchester, UK

SHARMA, J. K.; SINGH, D.; DEEPAK, K. K.; AGRAWAL, D. P. (2010) Neuromarketing: A Peep Into Customers Minds, PHI Learning, ISBN: 9788120338685

SMIDTS, A. (2012) The Future of Neuromarketing, NeuroRelay, http://neurorelay.com/2012/06/03/prof-dr-ale-smidts-the-future-of-neuromarketing/

SZCZEPANSKI, S. M.; SAALMANN, Y. B. (2013) Human fronto-parietal and parietohippocampal pathways represent behavioral priorities in multiple spatial reference frames.

BioArchitecture v. 3, p. 1-5.

THOMAS, A. R.; POP, N. A.; IORGA, A. M.; DUCU, C. (2017) Ethics And Neuromarketing: Implications For Market Research And Business Practice. Springer International Publishing AG, Switzerland

THE GUARDIAN. (2004) Coca Or Pepsi? It Is All In The Head!. Science And Research Of Professor Read Montague Of Baylor College Of Medicine In Houston, Texas

TOUHAMI, Z. O.; BENLAFKIH, L.; JIDDANE, M.; CHERRAH, Y.; MALKI, H, O.; BENOMAR, A. (2011) Neuromarketing: Where marketing and neuroscience meet. African Journal of Business Management, v. 5, n. 5, p. 1528-1532

ZALTMAN, G. (2003) How Customers Think: Essential Insights Into The Mind Of The Market. Harvard Business School Press, Boston, Massachusetts, USA

ZURAWICKI, L. (2010) Neuromarketing. Exploring the brain of the consumer. Springer Science \& Business Media, ISBN 3540778292, 9783540778295

WWW1: Neuromarketing Technology Market Size, Demand, Trends and Growth by Business Opportunities, Latest Innovation, Technology Trends and Forecast, https://www.reuters.com/brandfeatures/venture-capital/article?id=34591

WWW2: Neuroscience Market Size, Share \& Trends Analysis Report By Technology (Whole Brain Imaging, Neuromicroscopy, Electrophysiology), By Component, And Segment Forecasts, 2012 - 2020, https://www.grandviewresearch.com/industry-analysis/neurosciencemarket 
ISSN: $2236-269 X$

DOI: 10.14807/ijmp.v11i1.993

WWW3: Neurostimulation Devices Market Overview.

https://www.variantmarketresearch.com/report-categories/medical-devices/neurostimulationdevices-market

WWW4: COMMERCIAL ALERT (2008) Commercial Alertasks University To Halt.

Neuromarketingexperiments.Commercial Alert News Release.

http://www.Commercialalert.Org/Pdfs/Neuromarketingrel.Pdf 